\title{
PERANCANGAN PENINGKATAN FUNGSI HUNIAN MASYARAKAT DI LINGKUNGAN PARIWISATA UNTUK MENUNJANG PEREKONOMIAN DI TAMPAKSIRING
}

\author{
I Made Juniastra \\ Program Study Teknik Industri, Fakultas Teknik, Universitas Mahendradatta \\ JI. Ken Arok No. 12 Peguyangan, Denpasar, Bali 80115 \\ Email : juniastra@gmail.com
}

\begin{abstract}
Abstrak - Perkembangan jaman dewasa ini menuntut manusia untuk lebih kreatif dalam melihat potensi sebagai sumber pendapatan. Untuk rumah yang berada di lokasi pariwisata, rumah tidak hanya berfungsi sebagai tempat tinggal, tapi juga mempunyai nilai ekonomis yang tinggi, yaitu bisa disewakan dan dikombinasikan dengan usaha lain sehingga memaksimalkan fungsi dari rumah tersebut. Mancingan adalah salah satu daerah di Tampaksiring yang mempunyai potensi wisata alam yang sangat besar. Wisatawan dari domestik sampai mancanegara banyak yang berwisata ke Tampaksiring, karena menawarkan wisata alam berbasis kearifan lokal yang menjadi ciri khas tersendiri. Potensi ini merupakan hal yang sangat potensial untuk dimanfaatkan oleh masyarakat setempat untuk meningkatkan taraf perekonomian keluarga dengan tetap melestarikan tradisi Bali. Di Tampaksiring masih belum banyak ada sarana akomodasi, sehingga merupakan peluang yang sangat besar bagi masyarakat lokal untuk memanfaatkan kondisi tersebut. Umumnya tanah dari rumah masyarakat setempat sangat luas dan banyak space kosong, hal ini karena masih kental dengan penerapan konsep Arsitektur Tradisional Bali yang memang bercirikan hal tersebut. Hunian-hunian tempat tinggal bisa dimanfaatkan dengan perencanaan khusus untuk dijadikan tempat tinggal sekaligus difungsikan sebagai kamar sewa. Perencanaan sirkulasi mutlak harus menjadi pertimbangan yang utama untuk menentukan penzoningan ruang-ruang di dalamnya agar memiliki privasi dan kenyamanan yang optimal. Posisi ruang tidur baik untuk digunakan keluarga ataupun yang di sewakan mutlak harus mendapat pemandangan yang positif, sekaligus juga pencahayaan dan penghawaan alami untuk memaksimalkan potensi site ke dalam bangunan. Demikian juga untuk konsep Arsitektur Tradisional Bali berupa natah sebagai open space yang merupakan pusat orientasi bangunan tetap diterapkan dalam hunian ini, karena merupakan sumber kekuatan dari lingkungan itu sendiri. Dalam merancang tampilan bangunan juga tetap mengacu pada Arsitektur Tradisonal Bali, yaitu konsep Tri Angga yang membagi bangunan secara imajener menjadi Kaki, Badan, dan Kepala. Dalam penerapannya tetap dikombinasikan dengan Arsitektur Tropis Modern untuk menunjang fungsi bangunan yang lebih komplek.
\end{abstract}

Kata Kunci: perancangan kamar sewa, arsitektur tradisional bali, arsitektur tropis modern

Abstract - Today's development requires humans to be more creative in seeing potential as a source of income. For a house that is in a tourism location, the house not only functions as a residence, but also has a high economic value, which can be rented and combined with other businesses so as to maximize the function of the house. Mancingan is one of the areas in Tampaksiring that has a huge natural tourism potential. Many domestic and foreign tourists travel to Tampaksiring, because they offer natural tourism based on local wisdom which is their own characteristic. This potential is a very potential thing to be utilized by the local community to improve the level of the family's economy while still preserving the Balinese tradition. In Tampaksiring there are still not many accommodation facilities, so it is a huge opportunity for local people to take advantage of these conditions. Generally the land from local people's houses is very wide and there is a lot of empty space, this is because it is still thick with the application of the Traditional Balinese Architecture concept which is characterized by this. Residential dwellings can be used with special planning to be used as a residence as well as 
functioning as a rental room. Circulation planning absolutely must be the main consideration to determine the zoning of the spaces in it to have optimal privacy and comfort. The position of the bedroom is good for family use or rented absolutely must get a positive view, as well as natural lighting and air to maximize the potential of the site into the building. Likewise for the concept of Traditional Balinese Architecture in the form of Natah as open space which is the center of the orientation of the building is still applied in this residence, because it is a source of strength from the environment itself. In designing the appearance of the building also still refers to the Traditional Balinese Architecture, namely the concept of Tri Angga which divides the building imaginatively into Legs, Bodies, and Heads. In its application, it is still combined with Modern Tropical Architecture to support more complex building functions.

Keywords: rental room design, traditional balinese architecture, modern tropical architecture

\section{PENDAHULUAN}

Bali adalah pulau dengan destinasi wisata terbaik di dunia. Pertumbuhan pariwisata di Bali sangat baik dari tahun ke tahun. Demikian juga kebutuhan untuk sarana penunjangnya seperti akomodasi terus berkembang sejalan dengan pertumbuhan industri pariwisata. Masyarakat lokal haruslah menjadi subyek pembangunan tersebut sehingga masyarakat lokal bisa menikmati potensi wisata tersebut. Pariwisata di Bali sangat erat kaitannya dengan adat dan tradisi yang bersumber dari penerapan ajaran agama Hindhu yang dianut oleh mayoritas penduduk Bali. Oleh karena itu adat, tradisi, dan ritual keagamaan haruslah tetap dijaga dan diterapkan dalam keseharian masyarakat Bali (Juniastra, 2019).

Desa Tampaksiring adalah sebuah desa di Kabupaten Gianyar bagian utara, Provinsi Bali dengan kondisi alam yang sangat subur dan suhu udara yang sejuk. Di Tampaksiring ada beberapa destinasi pariwisata yang berbasis potensi alam. Bahkan ada DAS Tukad Pakerisan yang dijadikan Warisan Budaya Dunia yang sekaligus juga merupakan destinasi wisata. Objek wisata di Tampaksiring mempunyai ciri khas tersendiri karena berkaitan dengan history /sejarah yang sangat unik. Diantaranya ada objek wisata Gunung Kawi, Penglukatan Tirta Empul, Penglukatan Pura Mengening, istana Presiden yang didirikan Bapak Proklamator Ir. Soekarno, dan objek wisata lainnya yang tersebar di beberapa titik.

Wisatawan yang berkunjung mulai dari wisatawan lokal, wisatawan domestik /nusantara, sampai wisatawan mancanegara. Walaupun kunjungan wisatawan yang sedemikian banyaknya, namun di Tampaksiring belum banyak tersedia fasilitas akomodasi. Wisatawan umumnya menginap di daerah Ubud, Gianyar kota, Sanur, sampai di Nusa Dua. Masyarakat saat ini memanfaatkan ramainya kunjungan wisatawan hanya dari berjualan kerajinan seni dan membuka warung makan. Hal ini tentu merupakan kondisi yang memprihatinkan bagi masyarakat sekitar, karena tidak bisa menerima manfaat yang maksimal dari daerah wisata di wilayahnya.

Mancingan adalah sebuah dusun di Desa Manukaya, Kecamatan Tampaksiring yang berlokasi sangat dekat dengan objek wisata Tirta Empul, istana Presiden, dan penglukatan pura Mengening. Kondisi alamnya yang di sekelilingnya adalah persawahan dan dekat dengan WBD DAS Pakerisan yang biasa dijadikan paket wisata jalan di persawahan, sangat mungkin untuk dikembangkan fasilitas akomodasi berbasis masyarakat lokal. Sarana akomodasi ini memanfaatkan rumah-rumah warga yang umumnya memiliki lahan yang luas yang di fungsikan selain sebagai tempat tinggal keluarga itu sendiri dan juga di tambahkan kamar-kamar yang bisa di sewakan kepada wisatawan.

Hal ini menjadi akan menjadi kelebihan tersendiri bagi wisatawan bisa menginap dengan suasana desa di Bali yang sangat kental. Interaksi dengan masyarakat, kenyamanan menginap di rumah warga, dengan suasana alam yang masih alami tentu merupakan daya tarik tersendiri yang 
dimiliki Dusun mancingan. Namun demikian wisatawan tentu mengharapkan fasilitas kenyamanan yang maksimal yang standar baik dari segi luasan ruangan, fasilitas kamar, dan juga kebersihan seperti fasilitas umumnya mereka dapatkan di Daerah Ubud ataupun Nusa Dua.

Tujuan dari perancangan ini adalah untuk meningkatkan standar akomodasi lokal menuju ke level yang lebih baik sesuai dengan penerapan kaidah-kaidah Arsitektur Tradisional Bali sebagai kearifan lokal, dan dikombinasikan dengan Arsitektur Tropis Modern sesuai dengan kebutuhan fungsi dan kondisi alam di daerah tropis. Bangunan dirancang mengikuti potensi site di Dusun Mancingan yang mempunyai kemiringan yang cukup terjal, agar tetap menyatu dengan lingkungan sekitar dan penerapan Perda tentang ketinggian bangunan di Bali.

\section{METODE}

Metode yang di gunakan dalam perancangan ini adalah pengumpulan data dengan metode programatik, dan dalam tahapan perancangan menggunakan metode pragmatis. Yang dilakukan pertama adalah tahapan pengumpulan data untuk mengetahui lokasi dan potensi tapak, dan juga kebutuhan ruang yang ideal mewadahi fungsi hunian dan kamar sewa. Kemudian dilanjutkan dengan tahap analisis sintesis dengan metode pragmatis terhadap tapak dan bangunannya.

Tahap perancangan adalah tahap perumusan konsep dari analisis yang sudah di lakukan sebelumnya. Pada tahap ini dipergunakan metode pragmatis agar mendapatkan parameter yang detail tentang hunian dan kamar sewa dengan mengikuti peraturan yang ada sesuai acuan perancangan. Setelah tahapan perancangan maka didapatkan hasil desain sesuai dengan fungsi dan juga potensi tapak.

\section{HASIL DAN PEMBAHASAN Analisis Dan Konsep Tapak}

Tapak berada di banjar mancingan, desa manukaya kecamatan tampaksiring. Luas tapak sekitar 32 Are dengan posisi di sebelah selatan jalan dengan ketinggian tanah halaman depan adalah sama dengan jalan dan menurun ke belakang. di belakang tapak adalah saluran air. Kondisi tapak adalah kecil didepan dengan lebar sekitar $13 \mathrm{M}$ dan memanjang kebelakang, serta luas dan lebar di belakang. Di samping tapak masih dalam satu pekarangan sudah ada bangunan bertingkat yang di gunakan untuk hunian keluarga.

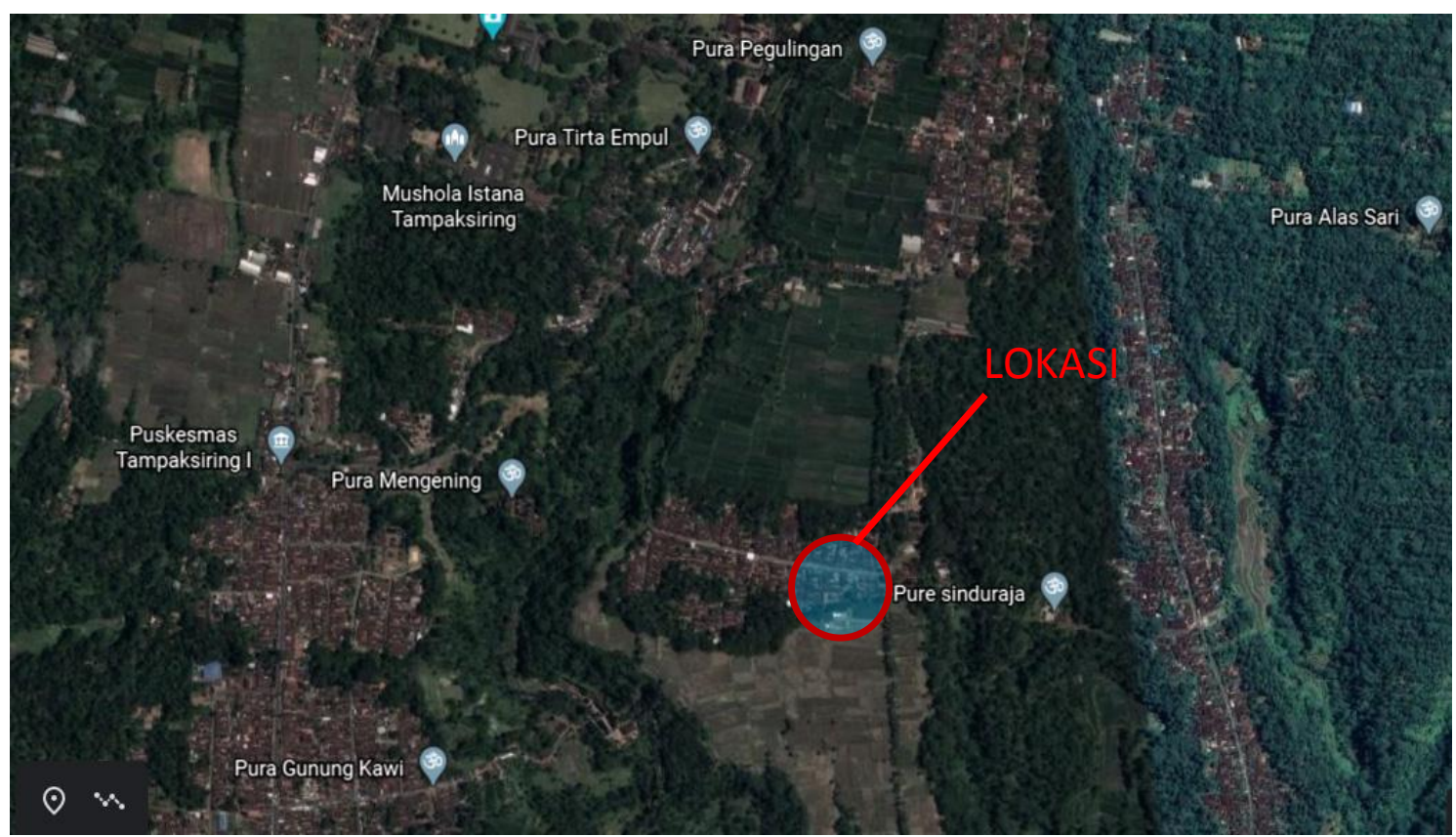

Gambar 1. Lokasi Tapak 
Koefisien dasar bangunan (KDB) sesuai Perda idealnya adalah $60-70 \%$ dari luas tapak. Namun karena bangunan yang akan di rancang posisinya di desa dimana konsep penataan bangunannya menggunakan konsep natah arsitektur tradisional bali, maka KDB tersebut sudah bisa dipenuhi. Konsep perencanaan adalah dengan memanfaatkan space yang tersedia tanpa mengganggu bangunan lain di sebelahnya. Untuk memaksimalkan fungsi dan pemanfaatan lahan, bangunan akan di tingkat ke atas dan juga ke bawah di bagian belakang sesuai dengan potensi site

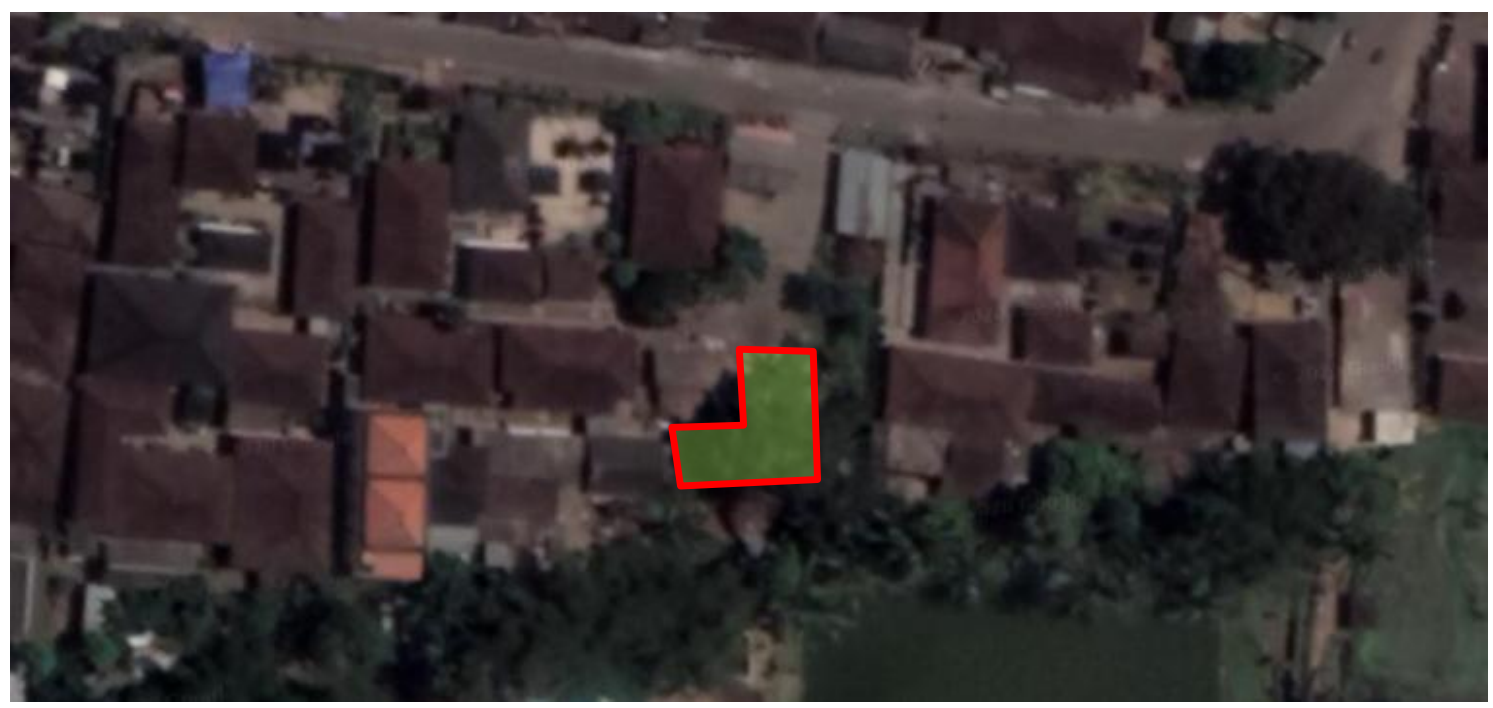

Gambar 2. Bentuk Tapak

\section{Analisis Dan Konsep Kebutuhan Ruang}

Berdasarkan hasil pengumpulan data melalui studi langsung dengan mengamati potensi tapak, interview dengan pemilik, study literature, serta study komparasi dengan bangunan akomodasi lainnya, maka didapatkan kebutuhan ruangruang sebagai berikut:

- Parkir

- Teras Depan Bersama

- Ruang Keluarga Masing-masing

- Dapur Masing-masing

- Kamar Tidur Pemilik + KM /WC

- Kamar Tidur Anggota Keluarga + Teras + KM /WC

- Kamar Sewa + KM /WC + Teras

- Teras Bersama

- Ruang Loundry + Jemur

- Kolam Renang

Bangunan yang akan dibangun konsep utamanya adalah rumah tinggal bagi pemilik. Pemilik mempunyai dua orang anak laki-laki dan juga keluarga mertua yang tradisi sering berkunjung. Hunian ini dipersiapkan kedepannya kalau anaknya sudah berumah tangga dan tetap tinggal di sana. Disamping itu juga disiapkan kamar sewa dan juga bisa dipakai sendiri kalau diperlukan. Untuk pengelolaan, kebersihan, perawatan kamar, dan lainnya akan dikelola sendiri dengan sistem bagi hasil bersama keluarga dekat seperti sepupu dan keponakan yang sehari hari bertani dan tinggal di rumah. Untuk fasilitas servis seperti laundry dan cuci jemur memanfaatkan area jemur keluarga yang sudah ada, sehingga tidak diperlukan tambahan space khusus.

Sesuai dengan kebutuhan ruang-ruang tersebut maka bisa di kelompokkan ruang-ruang sesuai dengan penzoningannya. Untuk area keluarga di pusatkan di depan sebagai titik mulai perancangan. Kemudian ditentukan zona kamar sewa yaitu di belakang, sekaligus view langsung ke persawahan. Fasilitas kolam renang sebagai area natah imajener sebagai pusat orientasi bangunan di bagian belakang. Akses sirkulasi dibuat memiliki privasi tersendiri. Untuk akses rumah tinggal dari depan seperti umumnya. Sedangkan untuk akses kamar sewa dari 
samping sekaligus memanfaatkan tangga bangunan yang langsung sampai di kolam renang, setelah itu baru menuju kamar masingmasing.

\section{Analisis Dan Konsep Pelaku, Aktivitas Dan Besaran Ruang}

Aktivitas sirkulasi pelaku di dalam tapak di polakan berdasarkan pola hierarki (konfigurasi ruang), sirkulasi dan aktivitas. Masing-masing pelaku diidentitaskan sesuai dengan fungsi dan aktivitasnya di dalam bangunan. Kemudian dari aktivitas tersebut bisa ditentukan kebutuhan ruangnya secara lebih spesifik. Kemudian langkah selanjutnya adalah menentukan faktorial dari kebutuhan ruang agar bisa ditentukan bentuk awal massa bangunan. Analisis ini berpedoman pada data dan literatur yang didapat saat pengumpulan data dengan pemilik homestay dan dikomparasi dengan literaturliteratur yang sesuai. Proses analisis dapat dilihat pada gambar berikut.

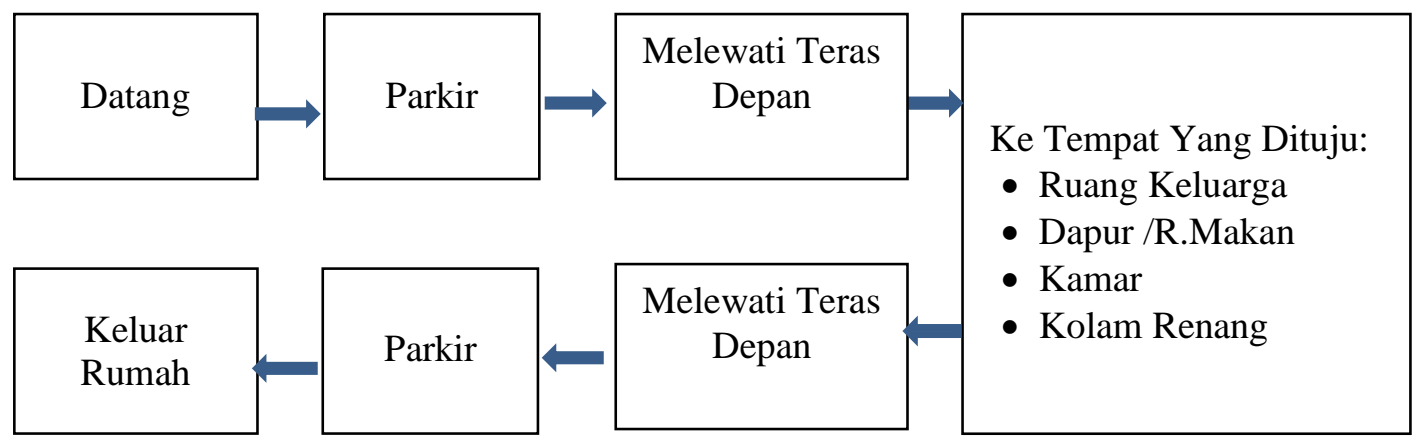

Gambar 3. Diagram Urutan Aktivitas Penghuni Rumah

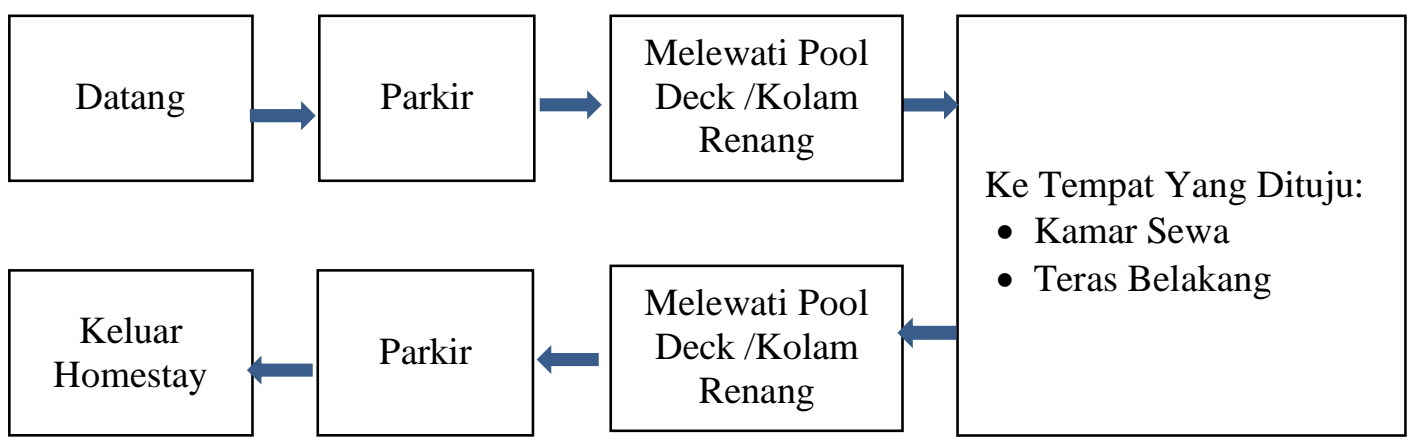

Gambar 4. Diagram Urutan Aktivitas Tamu /Pengunjung

Dari hasil pengumpulan data dari interview ruang yang diperlukan yang tersaji dalam tabel langsung dan beberapa literatur, diperoleh ruang berikut ini:

Tabel 1. Analis Pelaku, Aktivitas, Dan Besaran Ruang

\begin{tabular}{|l|l|l|c|c|c|}
\hline No & Nama Ruangan & \multicolumn{1}{|c|}{ Fungsi } & Jumlah & $\begin{array}{c}\text { Kebutuhan } \\
\text { Ruang }\end{array}$ & $\begin{array}{c}\text { Faktorial } \\
\text { Ruang }\end{array}$ \\
\hline 1 & Area Parkir & Parkir Kendaraan & 1 & $18,8 \mathrm{~m} 2$ & $4,7 \times 4 \mathrm{~m} 2$ \\
\hline 2 & Teras Bersama & $\begin{array}{l}\text { Tempat Berkumpul } \\
\text { Bersama Keluarga Sepupu, } \\
\text { Atau Tamu }\end{array}$ & 2 & $19,25 \mathrm{~m} 2$ & $7 \times 2,75 \mathrm{~m} 2$ \\
\hline 3 & $\begin{array}{l}\text { Ruang Keluarga + } \\
\text { Pantry }\end{array}$ & $\begin{array}{l}\text { Tempat Berkumpul } \\
\text { Keluarga Inti }\end{array}$ & 2 & $22,75 \mathrm{~m} 2$ & $3,5 \times 6,5 \mathrm{M} 2$ \\
\hline 4 & Kamar Tidur & Tempat Tidur Pribadi & 4 & $15,75 \mathrm{~m} 2$ & @ 4,5 x 3,5 m2 \\
\hline
\end{tabular}




\begin{tabular}{|c|c|c|c|c|c|}
\hline & Keluarga & & & & \\
\hline 5 & $\begin{array}{l}\mathrm{Km} / \mathrm{Wc}+\mathrm{R} . \\
\text { Lemari Dalam } \\
\text { Kamar Pribadi }\end{array}$ & Mandi + Ruang Baju & 4 & $7 \mathrm{~m} 2$ & $@ 2 \times 3,5$ m2 \\
\hline 6 & $\begin{array}{l}\text { Kamar Tidur } \\
\text { Sewa }\end{array}$ & Kamar Tamu /Disewakan & 4 & $\begin{array}{c}15,75 \mathrm{~m} 2 \\
\mathrm{~m} 2\end{array}$ & @ 4,5 x 3,5 m2 \\
\hline 7 & $\begin{array}{l}\mathrm{Km} / \mathrm{Wc}+\mathrm{R} . \\
\text { Lemari Dalam } \\
\text { Kamar Sewa }\end{array}$ & Mandi + Ruang Baju Tamu & 6 & $7 \mathrm{~m} 2$ & @ 2 x 3,5 m2 \\
\hline 8 & Kolam Renang & Berenang, View Positif & 1 & $32,5 \mathrm{~m} 2$ & $5 \times 6.5 \mathrm{~m} 2$ \\
\hline 9 & Pool Deck & $\begin{array}{l}\text { Area Duduk Di pinggir } \\
\text { Kolam Renang }\end{array}$ & 1 & $12,5 \mathrm{~m} 2$ & $5 \times 2,5 \mathrm{~m} 2$ \\
\hline 10 & Teras Bersama & $\begin{array}{l}\text { Berkumpul Tamu dan } \\
\text { bersantai }\end{array}$ & 1 & $32 \mathrm{~m} 2$ & $4 \times 8 \mathrm{~m} 2$ \\
\hline
\end{tabular}

Dari data kebutuhan ruang diatas dan potensi tapak dengan kemiringan lebih rendah di bagian belakang, perlu dilakukan split level lantai bangunan untuk menampung semua aktivitas yang diperlukan. Dari hasil analisa dan konsep diatas, didapat tatanan ruang dan tampilan bangunan sebagai berikut.

\section{Analisa Dan Konsep Bangunan Lantai Bawah}

Ketinggian lahan di zona ini yang paling rendah, yaitu rata dengan persawahan di belakang. Level tanah pada zona ini lebih rendah 2 meter dari level diatasnya. Pada zona ini diletakkan fungsi untuk kamar sewa pada sayap kiri dan sayap kanan. Sedangkan di tengah adalah space untuk kolam renang di lantai dasar (diatasnya).

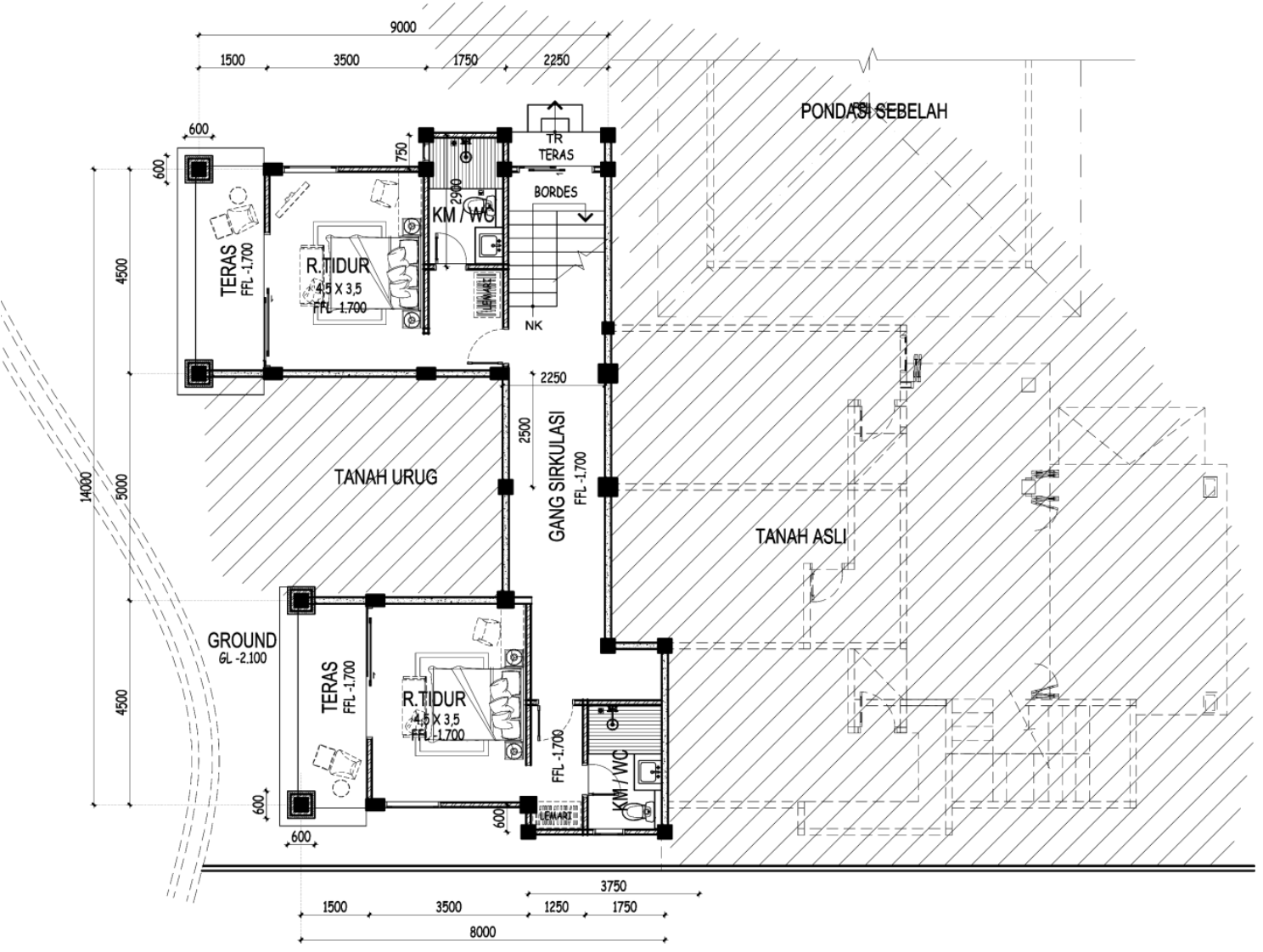

Gambar 5. Denah Lantai Bawah 


\section{Lantai Dasar}

Pada lantai dasar ini direncanakan untuk menampung fungsi utama dari rumah tinggal. Mulai dari area parkir, teras bersama, ruang keluarga 1 dan ruang keluarga 2 disertai pantry pada masing masing ruang keluarga, kamar tidur keluarga, dan dibagian belakang untuk space kamar sewa. Pusat orientasi bangunan bagian belakang juga ditempatkan di lantai ini yaitu berupa kolam renang beserta pool deck nya. Dari kolam renang bisa dinikmati view positif di belakang tapak yaitu berupa persawahan yang menghampar luas seperti tidak berujung. Sawah di bagian belakang ini juga sering dilalui oleh banyak wisatawan untuk jalan lintas alam baik bersama pasangan ataupun berkelompok. Akses ke lantai ini bisa dicapai dari depan ataupun dari samping kanan, yaitu dari tangga samping. Untuk sirkulasi tamu nantinya, disiapkan melalui tangga samping, sedangkan untuk sirkulasi keluarga disiapkan melalui tangga depan. Posisi tangga sangat penting untuk menunjang efektifitas dan kenyamanan sirkulasi bangunan secara vertikal. Bagian teras depan dibuat seolah olah terbuka dan disekat oleh pintu kaca yang lebar dan tinggi. Ini bertujuan agar terkesan terbuka layaknya teras teras bangunan bali pada umumnya. Teras ini juga berfungsi untuk menampung tamu undangan kalau keluarga sepupu yang tinggal di samping punya acara, sehingga memerlukan ruang yang luas. Teras ini juga dibuat seolaholah menyatu dengan area parkir di depannya yang nanti kalau diperlukan juga bisa difungsikan untuk menampung tamu.

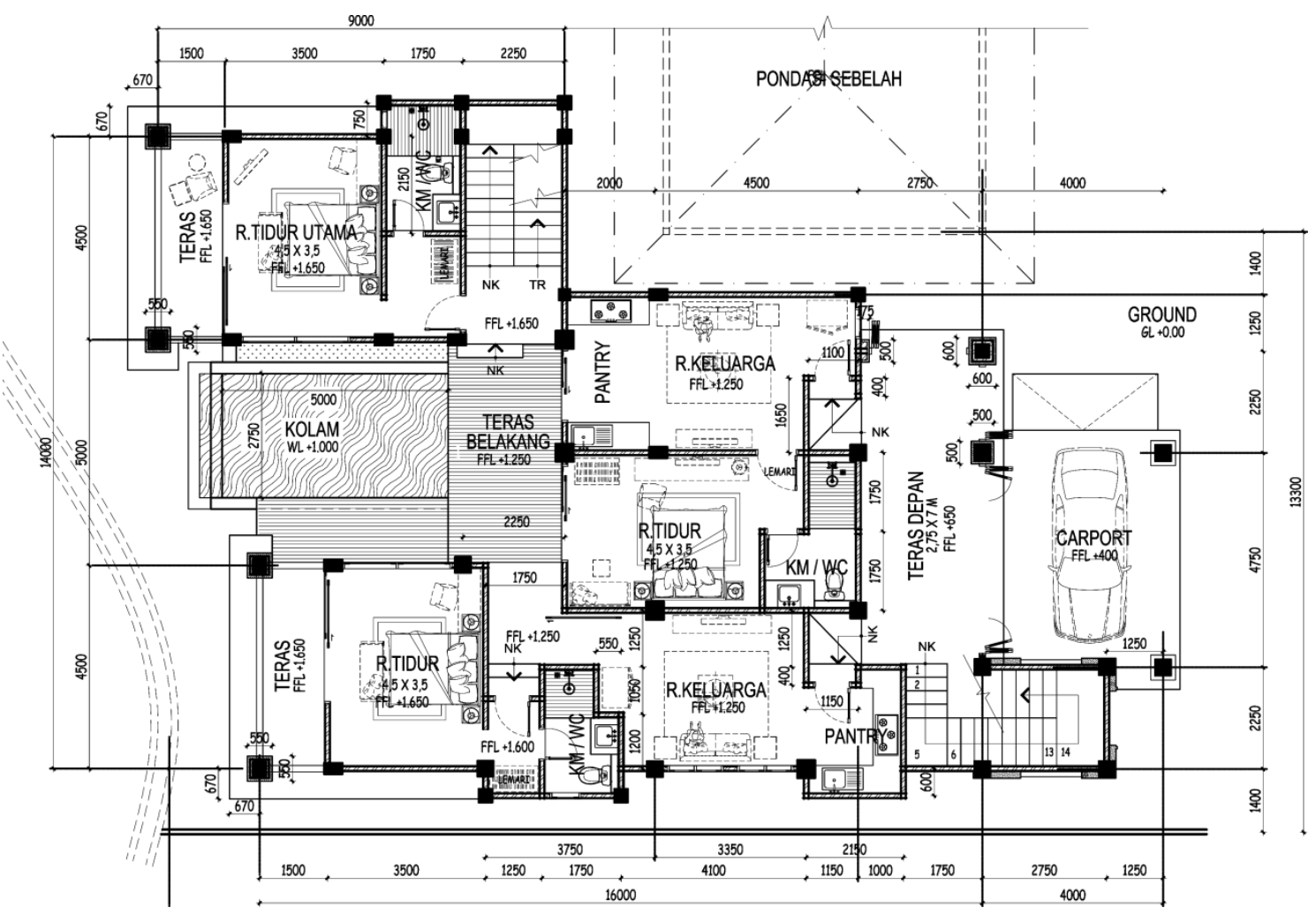

Gambar 6. Denah Lantai Dasar

\section{Lantai Atas}

Lantai atas bagian depan difungsikan untuk area keluarga, yaitu dengan fasilitas ruang keluarga dan ruang tidur keluarga. Disamping itu ruang keluarga atas ini juga terkoneksi langsung dengan teras atas depan yaitu posisinya diatas area parkir. Ruang keluarga dan teras terbuka ini di buat dengan konsep semi publik. Keluarga dekat atau sepupu masih bisa mengakses ke area ini. Ini menunjukkan kondisi keguyuban di daerah tersebut, diamana masih kental sekalai rasa kekeluargaan. Di bagian belakang di tempatkan fungsi teras bersama dan kamar sewa. Akses ini bisa dicapai dari tangga depan ataupun dari tangga samping. 
Dari area ini terhampar view positif di belakang bangunan. Udara yang segar dan alami serta pemandangan yang hijau menghampar sungguh merupakan daya tarik tersendiri bagi bangunan di tapak tersebut.

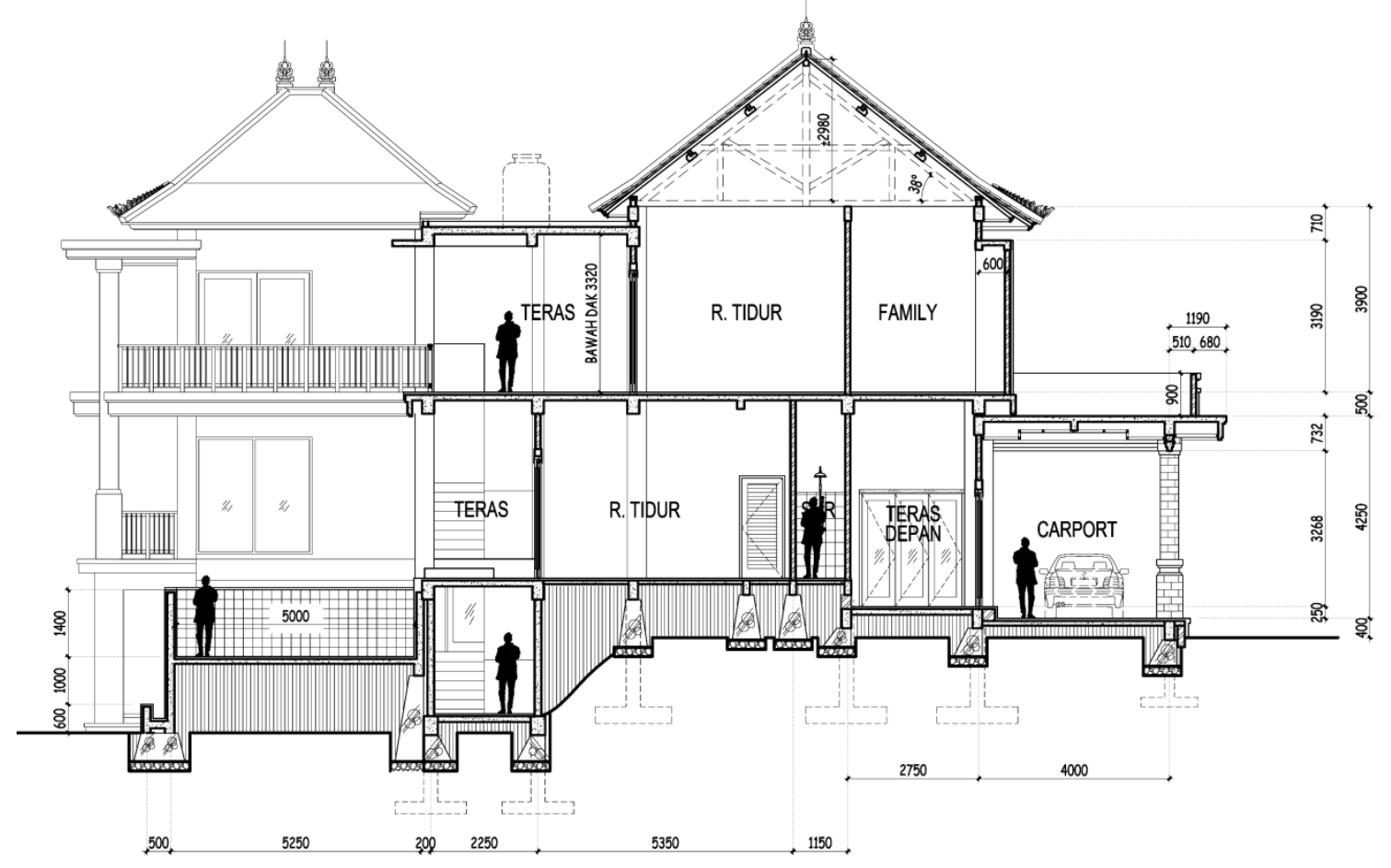

Gambar 7. Potongan Split Level Posisi Tapak

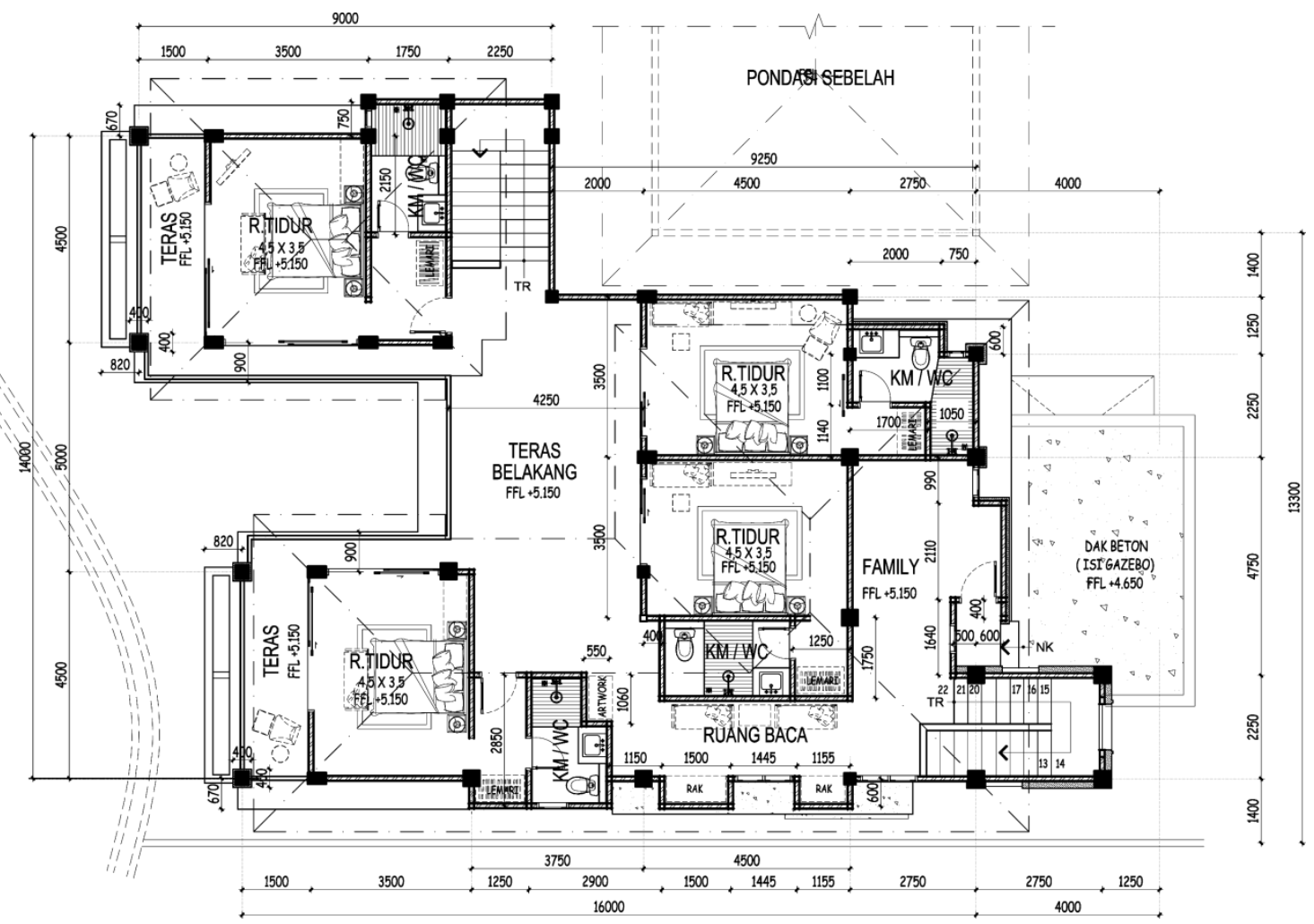

Gambar 8. Denah Lantai Atas 


\section{Analisis dan konsep ruang dalam}

Ruang dalam dikonsep dengan baik untuk kenyamanan fungsi dan aktivitas di dalam ruangan. Pencahayaan dan penghawaan natural /alami dipertahankan meskipun nanti dikombinasikan dengan penghawaan buatan (AC). Dan dalam kesehariannya bisa di buka dan ditutup sesuai dengan kondisi cuaca di luar. Untuk meuble dipilih dari bahan kayu jati yang sudah dikeringkan, agar memudahkan perawatan. untuk pewarnaan /finishing meubel dan kusen pintu dan jendela menggunakan warna nuansa alami kayu. Untuk tembok dan plafon menggunakan cat nuansa putih dan pastel sehingga terkesan bersih, luas, dan lapang. interior direncanakan dengan konsep simple namun elegan, dalam artian fungsional /tidak berlebihan. Hal tersebut dimaksudkan untuk menampilkan karakter lingkungan alami yang kuat, dan juga untuk meminimalkan biaya agar lebih efisien. karena biaya pembangunan akan berpengaruh terhadap harga jual kamar sewa.

\section{Analisa dan konsep tampilan}

Bentuk dan tampilan hunian sebagaimana layaknya bangunan di Bali yang terikat oleh Arsitektur Tradisional Bali, tetap menggunakan Konsep Tri Angga, yaitu dengan pengandaian bentuk tubuh manusia sebagai mahluk ciptaan
Tuhan yang paling sempurna yang terdiri dari Kaki, Badan, dan Kepala. Konsep ini diterapkan dengan transformasi ke dalam tampilan bangunan yang juga mempunyai unsur Kaki, Badan, dan Kepala. Unsur Kaki adalah pondasi sampai lantai bangunan. Unsur Badan adalah ruang-ruang bangunan, yaitu diatas lantai. Sedangkan unsur Kepala adalah atap bangunan yang di Bali berbentuk limasan dengan sudut kemiringan antara $38^{\circ}-45^{\circ}$ yang diproporsikan dengan lebar serta tinggi bangunan.

\section{Pembahasan Hasil Desain}

Bangunan ini difungsikan untuk rumah tinggal dan juga kamar sewa. Oleh karena itu penataan ruang ruang dan sirkulasinya harus benar benar diperhatikan agar masing masing fungsi yang diwadahinya memiliki privasi yang cukup. Kondisi site dengan kemiringan menurun ke arah belakang dimanfaatkan untuk menambah lantai bangunan dengan sistem split level. Dalam hal ini juga sangat diperhatikan ketinggian ruangan di tiap lantai supaya tidak terlalu tinggi ataupun terlalu rendah. Agar masing masing ruangan menjadi positif maka ditempatkan kolam renang di area terbuka bagian belakang yang dalam arsitektur tradisional Bali disebut natah yaitu sebagai pusat orientasi rumah.
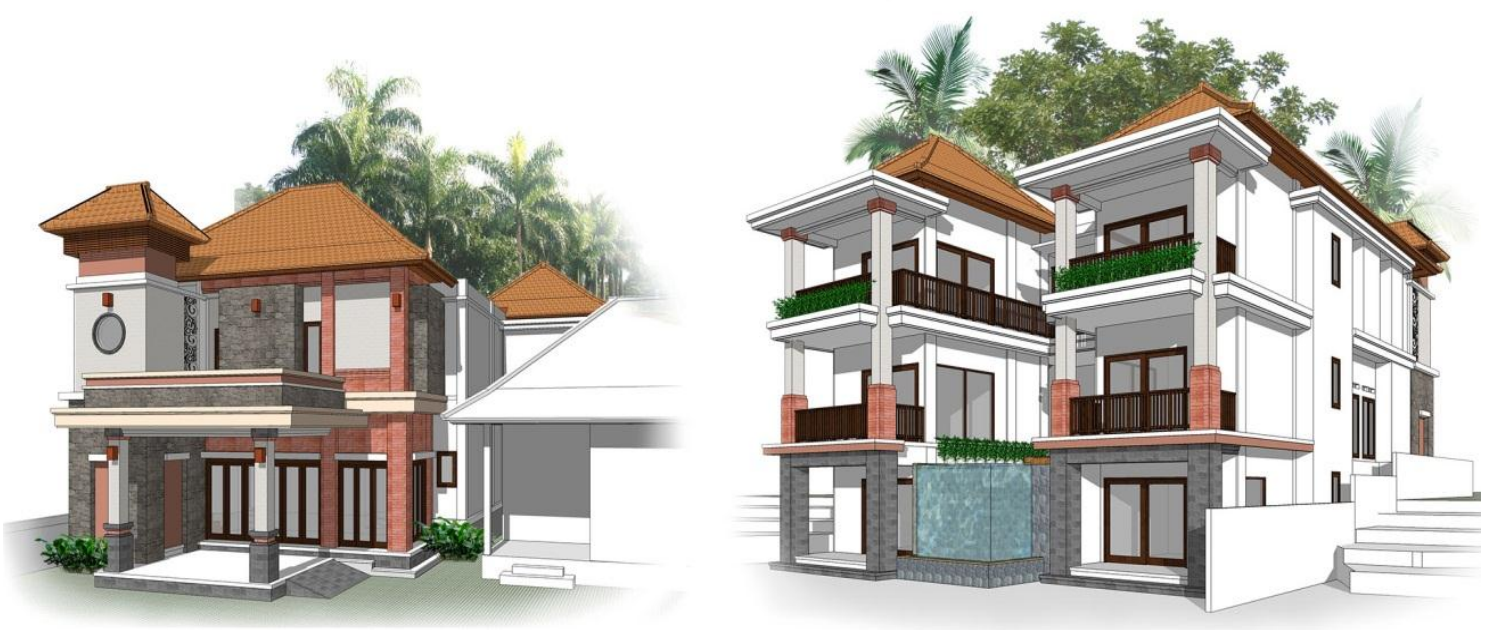

Gambar 9. Tampilan Depan Dan Tampilan Belakang 

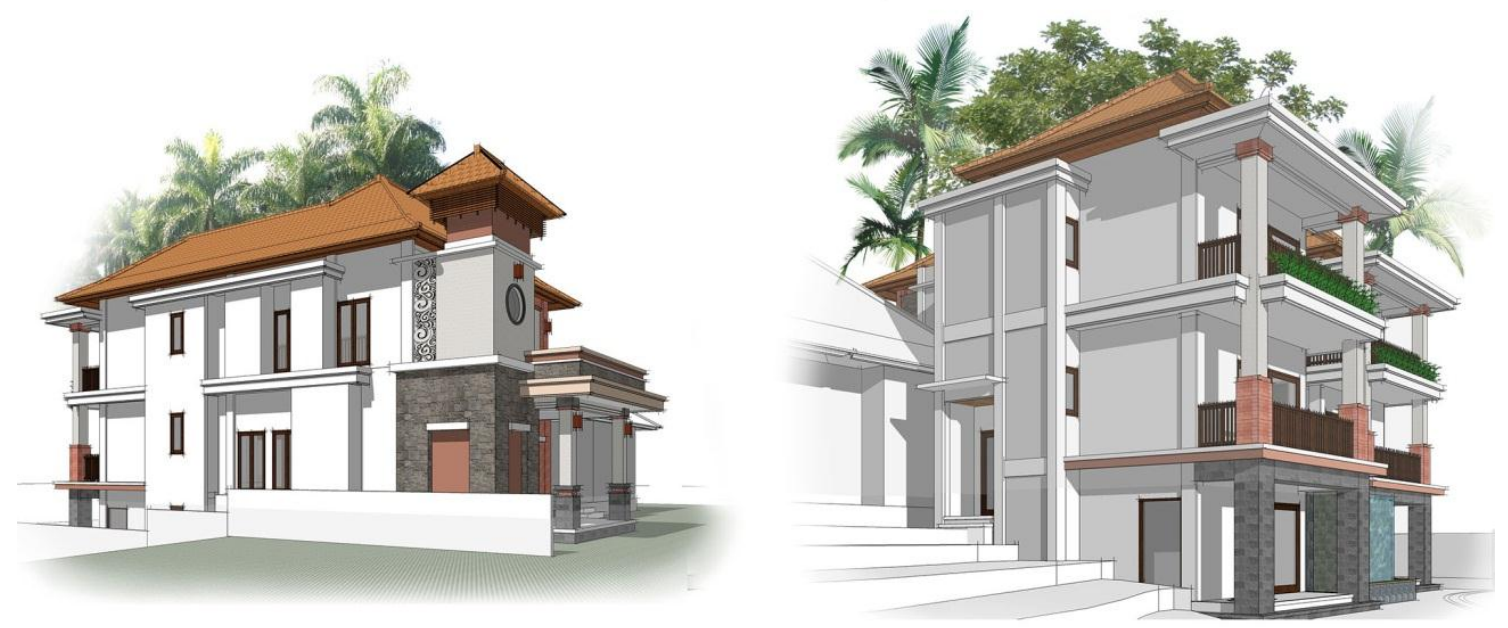

Gambar 10. Perspektif Sudut Depan Dan Belakang

Untuk material finishing bangunan sebagian besar di plester dan aci, serta difinishing denga cat nuansa putih atau warna pastel. Konsep ini dimaksudkan untuk menyimbulkan bangunan yang modern, bersih dan ramah terhadap lingkungan. Dinding depan di tempel dengan bata press expose yang ditampilkan karakter alaminya, yang mengesankan bangunan modern dan menyatu dengan lingkungan yang sebagian besar bernuansa paras bata. Pada bagian kolom ditempel dengan batu alam untuk mengesankan kokoh dan megah. Bagian depan di buat sebuah bentuk tower yang mencerminkan balai kul-kul dalam tradisi Bali untuk mengesankan bangunan yang menjadi point of interest dari lingkungan sekitar. Atap menggunakan atap genteng kodok yang terbukti awet dan tidak mudah pecah untuk meminimalisir perawatan di kemudian hari. Atap atap genteng tidak dipaksakan menyatu yang menyebabkan akan banyak talang air yang menambah risiko bocor. Akan tetapi posisi yang kurang bagus disambung dengan dak beton untuk mempermudah perawatan. disamping itu dak beton juga berfungsi untuk menempatkan tandon air untuk utilitas bangunan. Kaidah Arsitektur Tradisional Bali sebagai kearifan lokal yang merupakan sumber dari kekuatan pariwisata Bali tetap diterapkan baik pada penataan ruang (konsep nawa sanga - huluteben) maupun pada tampilan bangunan (konsep tri angga). Bukaan-bukaan jendela yang lebar dikombinasi dengan ventilasi bagian atasnya untuk memanfaatkan pencahayaan alami dan penghawaan alami.

\section{KESIMPULAN}

Dalam perencanaan dan perancangan hunian denga kamar sewa, hal-hal yang harus diperhatikan adalah:

- Mengidentifikasi tapak dengan segala potensinya, dan dimanfaatkan untuk dikembangkan secara optimal;

- Tahap pengumpulan data dilakukan dengan detail, baik tentang ide dari pemilik, kebutuhan ruang untuk mewadahi fungsi yang akan ditampungnya, ataupun ada halhal tertentu yang khusus yang mesti mendapat perhatian, baik dengan wawancara lisan dengan pemilik, dengan study literatur, dan study perbandingan dengan bangunan sejenis lainnya;

- Perencanaan bangunan baik dalam penataan ruang dan juga tperencanaan tampilan bangunan harus tetap harus berpedoman pada kaidah Arsitektur Tradisional Bali. Karena kearifan lokal Bali tersebut merupakan sumber taksu /kekuatan dari pariwisata Bali;

- Unsur-unsur tropis modern tetap harus dimasukkan untuk memperkuat nuansa arsitektur Bali, karena kebutuhan akan bangunan yang besar dan fungsi yang lebih kompleks; 
- Dalam penataan /penzoningan ruang-ruang tetap harus mengacu pada konsep Nawa Sanga /Hulu-Teben, yaitu arah timur atau utara sebagai hulu.

- Konsep Tri Angga tetap harus diterapkan dalam merancang tampilan bangunan, agar bangunan baru tersebut bisa harmonis dengan lingkungan sekitar.
DAFTAR PUSTAKA

Juniastra I Made. 2019. Re-Design Homestay Lokal Selaras Dengan Industri Pariwisata. Bali. Jurnal Vastuwidya.

Glebet I Nyoman,dkk. 1986. Arsitektur Tradisional Daerah Bali. Denpasar: Depdikbud Propinsi Bali. 